\title{
Creating a space for interprofessional engagement in a clinical setting
}

L Jaffer, MA, BA Hons, BA; L Africa, MSc, BSc; F Waggie, PhD, MSc, BSc

Interprofessional Education Unit, Faculty of Community and Health Sciences, University of the Western Cape, Bellville Campus, Cape Town, South Africa

Corresponding author: L Jaffer (ljaffer@uwc.ac.za)

Fundamental to interprofessional education (IPE) is the assertion that if health professional students learn together from the outset and throughout their academic studies and training, they will be better prepared to work collaboratively and effectively within an interprofessional team when qualified. ${ }^{[1]}$

In spite of the focus on the conceptualisation of IPE, ${ }^{[2,3]}$ student engagement and collaboration were in need of attention. This was evident in the clinical setting, as students continued working in their discipline-specific silos when practising.

The clinical setting was therefore identified as a platform in need of IPE-focused activities to facilitate and encourage students from different health professions to engage and collaborate with each other while completing their clinical rotations.

\section{What was tried? (Approach)}

Students received weekly on-site supervision from discipline-specific supervisors while on clinical rotations. During this time, the focus was purely on patient assessment and intervention from a discipline-specific standpoint. In addition, IPE-focused activity sessions were introduced for University of the Western Cape (UWC) health science students present at the same clinical site (i.e. hospital, community health centre, clinic) simultaneously. This overlap was identified by UWC IPE co-ordinators, based on the clinical rotation rosters provided to them by the various departments. Participating disciplines included physiotherapy, occupational therapy, dietetics, social work and pharmacy. Weekly 1-hour sessions comprised the IPE and collaborative practice (IPECP) programme for the duration of the respective students' clinical rotations - each session comprising $\sim 8-12$ students. Students brought along their case reports and shared these with each other as a means of obtaining additional information and input from other health disciplines. The IPECP planning framework was used to guide this process, where all aspects of a patient's treatment plan and intervention were explored. This framework is a combination of the Comprehensive Primary Health Care and the International Classification of Functioning, Disability and Health (ICF) frameworks (Fig. 1).

Students were encouraged to discuss their most challenging patients and gain input from the various disciplines present to develop holistic and collaborative treatment and intervention plans. As patient cases were unpacked, students began to develop a deeper understanding of the extent of the roles that various health

\begin{tabular}{|c|c|c|c|c|}
\hline & Rehabilitative & Curative & Promotive & Preventive \\
\hline \multirow{5}{*}{$\begin{array}{l}\text { Client/patient/ } \\
\text { vulnerable group/ } \\
\text { health issue (briefly } \\
\text { describe the issue and } \\
\text { develop a priority } \\
\text { list that must be } \\
\text { addressed by the team) }\end{array}$} & \multicolumn{4}{|c|}{ Impairment (changes in body structure) _. } \\
\hline & \multicolumn{4}{|c|}{ Activity (level of capacity in standard environment) } \\
\hline & \multicolumn{4}{|c|}{ Participation restriction (level of performance in usual environment) } \\
\hline & \multicolumn{4}{|c|}{$\begin{array}{l}\text { Environmental factors (household/transport/work environment/ } \\
\text { dependants/children) and personal factors (age/sex/medical history/ } \\
\text { lifestyle/habits) }\end{array}$} \\
\hline & \multicolumn{4}{|l|}{ Priority list } \\
\hline \multicolumn{5}{|l|}{$\begin{array}{l}\text { Aim of the } \\
\text { intervention }\end{array}$} \\
\hline \multicolumn{5}{|l|}{$\begin{array}{l}\text { Objectives: how will } \\
\text { these be achieved }\end{array}$} \\
\hline \multicolumn{5}{|l|}{$\begin{array}{l}\text { What: plan activities } \\
\text { for each objective }\end{array}$} \\
\hline \multicolumn{5}{|l|}{$\begin{array}{l}\text { Who: team and } \\
\text { their role }\end{array}$} \\
\hline \multicolumn{5}{|l|}{$\begin{array}{l}\text { How: appropriate } \\
\text { intervention }\end{array}$} \\
\hline $\begin{array}{l}\text { When: logistics, } \\
\text { e.g. date, time }\end{array}$ & & & & \\
\hline
\end{tabular}

Fig. 1. Interprofessional education collaborative practice planning framework. professionals play, and the necessity of working within a team to treat and care for a patient comprehensively.

\section{What lessons were learnt? (Outcomes)}

The success at the forefront of this programme was the positive and constructive manner in which students engaged in an interprofessional space. Prior to the IPECP programme, the majority of students had never spoken to each other or interacted, but merely passed each other in 


\section{Short Communication}

hallways and common spaces. Students reported that the IPECP programme had been the impetus behind a newfound confidence to approach not only fellow UWC students in the clinical setting, but also senior medical staff, physicians, specialists and others. The IPECP programme had significantly improved their understanding of the roles of other health professionals and their function within a team.

Declaration. None.

Acknowledgements. None.

Author contributions. All authors contributed equally to the article. Funding. None.

\section{Conflicts of interest. None.}

. Reeves S, Zwarenstein M, Goldman J, et al. Interprofessional education: Effects on professional practice and health care outcomes. Cochrane Database Syst Rev 2008;(1). https://doi.org/10.1002/14651858.CD002213.pub2

2. Barr H. Toward a theoretical framework for interprofessional education. J Interprof Care 2013;27(1):4-9. https:// doi.org/10.3109/13561820.2012.698328

3. Frantz JM, Rhoda AJ. Implementing interprofessional education and practice: Lessons from a resourceconstrained university. J Interprof Care 2017;31(2):180-183. https://doi.org/10.1080/13561820.2016.12 61097

Accepted 13 March 2020.

Afr J Health Professions Educ 2021;13(1):12-13. https://doi.org/10.7196/AJHPE.2021.v13i1.1316 